\title{
First description of the metopiine genus Trieces Townes, 1946 (Hymenoptera: Ichneumonidae) from the Indomalayan region with three new species from India
}

\author{
A.P. RANJITH ${ }^{\circledR 1, *} \&$ Dharma Rajan PRIYADARSANAN ${ }^{\circledR 2}$ \\ ${ }^{1,2}$ Insect Biosystematics and Conservation Laboratory, Ashoka Trust for Research in Ecology and \\ the Environment (ATREE), Royal Enclave, Srirampura, Jakkur Post, Bangalore 560064, India. \\ *Corresponding author: ridhuranjith@gmail.com \\ ${ }^{2}$ Email: priyan@atree.org \\ ${ }^{1}$ urn:1sid:zoobank.org:author:84D114CA-C3FD-475D-97C0-6143EEF6C715 \\ ${ }^{2}$ urn:lsid:zoobank.org:author:03907E93-F783-4720-9F7B-CB662E7FC745
}

\begin{abstract}
Trieces Townes, 1946 is one of the largest metopiine genera for which species have been described from all zoogeographical regions except the Indomalayan. The present study reports a major range extension of Trieces with the description of three new species from India. The described species are members of the onitis species group. An identification key to the Palearctic and Indomalayan species of the onitis group is included with the revised generic diagnosis and a key to separate Trieces from its closest genus Chorinaeus. Distribution pattern and character plasticity of Trieces are also discussed.
\end{abstract}

Keywords. Darwin wasps, Metopiinae, Karnataka, Nagaland, redefinition.

Ranjith A.P. \& Priyadarsanan D.R. 2022. First description of the metopiine genus Trieces Townes, 1946 (Hymenoptera: Ichneumonidae) from the Indomalayan region with three new species from India. European Journal of Taxonomy 794: 1-17. https://doi.org/10.5852/ejt.2022.794.1649

\section{Introduction}

The Darwin wasp subfamily Metopiinae Förster, 1869 comprises larval-pupal koinobiont endoparasitoids of Lepidoptera Linnaeus, 1758 (Gauld et al. 2002; Mazón \& Bordera 2016; Broad et al. 2018). This subfamily has more than 862 species in 27 genera (Yu et al. 2016). The metopiine genus Trieces Townes, 1946 includes 72 extant species distributed in all geographical regions except the Indomalayan region (Gauld et al. 2002; Tolkanitz 2010; Choi et al. 2016; Yu et al. 2016; Mazón \& Bordera 2020). The majority of species have been reported from the Nearctic and Neotropical region (Townes 1971; Gauld et al. 2002; Melo et al. 2015; Mazón \& Bordera 2016, 2020). Metopiines are reported as larval-pupal parasitoids of lepidopteran families like Elachistidae Bruand, 1850, Geometridae Leach, 1815, Pyralidae Latreille, 1809, Tortricidae Latreille, 1803, Yponomeutidae Stephens, 1829 and Oecophoridae Bruand, 1851 (Aeschlimann 1973, 1975; Tolkanitz 2010; Zhang et al. 2016; Broad et al. 2018). Most of the known species are reported from dry shrubby habitats (Townes \& Townes 1959; Zhang et al. 2016). 
Trieces can be separated from other metopiine genera by the absence of a mesopleural suture, the apomorphic character of the genus (Gauld et al. 2002). In addition to this, the absence of a pocket structure on the lower pronotum is found to be a possible synapomorphy to distinguish Trieces from related genera such as Chorinaeus Holmgren, 1858 and Hemimetopius Benoit, 1955. This genus is very similar to the genus Chorinaeus except for the following characters: mesopleuron without mesopleural suture; pronotum without dorso-lateral depression, and metasomal tergites 1-3 with a lateral carina (Townes \& Townes 1959; Townes 1971; Aeschlimann 1973; Gauld et al. 2002; Tolkanitz 2010). Even though Trieces and Chorinaeus are distinguishable by several characters, these genera are morphologically not well separated as at least one species, T. ranjithi Mazón \& Bordera, 2021, was found to be intermediate between them (Mazón \& Bordera 2020, 2021). An examination of more material and application of molecular phylogeny need to be done to resolve the taxonomic complication between Trieces and Chorinaeus and to delimit the species groups.

Townes \& Townes (1959) divided Trieces into four different species groups (dentatus, integer, onitis and texanus) based on morphology. The species of the onitis group can be defined by the presence of a posterior slit-like depression on the metapleuron (Townes \& Townes 1959; Tolkanitz 2010). This species group includes fewer than 10 species which are mostly distributed in the Palearctic region (Yu et al. 2016; Choi et al. 2016). The new species described in the present study belong to the onitis species group.

Gauld (1984) and Townes \& Townes (1959) mentioned the occurrence of species of Trieces in the Australian and Indomalayan regions, respectively (but yet to be described taxonomically). The present study reports on the distribution of Trieces for the first time from the Indomalayan region with the description of three new species, T. irwini sp. nov., T. isolatus sp. nov. and T. orientalis sp. nov. from India. Identification keys for the separation of Trieces from Chorinaeus and identification of Palearctic and Indomalayan species of the onitis group are provided along with illustrations of new species. The distribution pattern of species of Trieces and morphological delimitation of the onitis group are discussed.

\section{Material and methods}

Specimens for the present study were collected by Malaise traps from the dry deciduous and evergreen forests of Biligiri Rangaswamy Temple Tiger Reserve (BRT), Chamarajanagar District, Karnataka and secondary wet forest of Zapami Village, Phek District, Nagaland. The collected specimens were kept in $95 \%$ alcohol and later mounted on card points and identified. Images were taken with a Keyence VHX6000 digital microscope with a magnification of $200 \times$. Final images were edited in Adobe Photoshop CS8 for removing artifacts formed during stacking. Measurements of body parts were taken from the holotypes by AxioVision 4.8. The type material of the new species is deposited in the collection of ATREE Insect Museum, Bengaluru, India (AIMB). Later, holotypes of the new species will be moved to the national repository at NBAIR, Bangalore. For morphological terminology and wing venation we follow Broad et al. (2018). For body sculpture we follow Eady (1968).

\section{Institutional abbreviations}

$\mathrm{AIMB}=\mathrm{ATREE}$ Insect Museum, Bengaluru, India

NBAIR = National Bureau of Agricultural Insect Resources, Bengaluru, India 


\title{
Results
}

\section{Taxonomic account}

\author{
Class Insecta Linnaeus, 1758 \\ Order Hymenoptera Linnaeus, 1758 \\ Superfamily Ichneumonoidea Latreille, 1802 \\ Family Ichneumonidae Latreille, 1802 \\ Subfamily Metopiinae Förster, 1869
}

Genus Trieces Townes, 1946

Trieces Townes, 1946: 60. Type species: Exochus texanus Cresson, 1872.

\section{Diagnosis}

Eyes glabrous or sparsely setose, slightly emarginated near antennal torulus (Figs 1B, 3B, 5B). Face often wider than long (Figs 1B, 3B, 5B), rarely longer than wide, sometimes narrowing posteriorly (Figs 3B, 5B). Interantennal process distinct, acute (Figs 1B, 3B, 5B). Clypeus transverse, separated from face by shallow transverse impression, apical margin sharp and more or less truncate, weakly convex or slightly concave. Mandible often with upper and lower teeth, rarely lower tooth absent. Frons depressed, without midlongitudinal lamella (Figs 1C, 3C, 5C). Temple not bulged behind eyes in dorsal view (Figs 1C, 3C, 5C). Pronotum evenly convex without impression. Propleuron weakly swollen (Figs 1E, 3E, 5E). Mesonotum without notauli (Figs 1F, 3F, 5D). Scutoscutellar groove small, smooth (Figs 1F, 3F, 5D). Scutellum with distinct lateral carina (Figs 1F, 3F, 5D). Mesopleuron without sternaulus (Figs 1E, 3E, 5E). Epicnemial carina present and complete (Figs 1E, 3E, 5E). Mesopleural suture absent (Figs 1E, 3E, 5E). Metapleuron with or without longitudinal wrinkles and posterior slit (Figs 1E, 3E, 5E). Propodeum with distinct pleural carina and a pair of submedial carinae, posterior transverse carina absent (Figs 2A, $4 \mathrm{~A}, 5 \mathrm{~F}$ ). Fore and mid tarsal claws pectinate, hind tarsal claw simple. Fore wing without areolet (Figs $2 \mathrm{~B}$, $4 \mathrm{~B}, 6 \mathrm{C}$ ). Fore wing vein 1cu-a interstitial to postfurcal (Figs 2B, 4B, 6C). Hind wing vein CU1b absent. Metasomal tergites without laterotergites (Figs 2C, 4D, 6A). First metasomal tergite broad posteriorly with dorsal and dorso-lateral carinae (Figs 2D, 4C, 6B), and rarely with ventro-lateral carina (Fig. 2C). Spiracle of first metasomal tergite at anterior $1 / 3^{\text {rd }}$ (Figs $\left.2 \mathrm{C}, 4 \mathrm{D}, 6 \mathrm{~A}\right)$. Second metasomal tergite with midlongitudinal and lateral carinae (Figs 2D, 4C, 6B). Third metasomal tergite often with complete midlongitudinal carina and lateral carina (Figs 2D, 4C, 6B). Fourth metasomal tergite often without lateral carina (Figs 2C, 4D, 6A). Ovipositor slender apically (Fig. 4D).

\section{Distribution}

Though Yu et al. (2016) listed this as a cosmopolitan genus, there were no described species of this genus so far from the Indomalayan region.

\section{Biology}

Larval-pupal endoparasitoids of Lepidoptera particularly Tortricidae and Yponomeutidae (Gauld et al. 2002; Broad et al. 2018).

\section{Key to separate Trieces Townes, 1946 from Chorinaeus Holmgren, 1858}

1. Mesopleuron with mesopleural suture (Fig. 7A, C); lateral longitudinal carina only present on metasomal tergite 1 and base of second metasomal tergite (Fig. 7A, D-F); pronotum with dorsal longitudinal depression (Fig. 7B) (weak in C. brevicalcar Thomson, 1887)

Chorinaeus Holmgren, 1858 
- Mesopleuron without mesopleural suture (Figs 1E, 3E, 5E); lateral longitudinal carina present on metasomal tergites 1-3 (absent in T. ranjithi) (Figs 2D, 4C, 6B); pronotum without dorsal longitudinal depression (weakly present in T. flabenis Gauld \& Sithole, 2002) Trieces Townes, 1946

\section{Key to the Palearctic and Oriental species of Trieces Townes, 1946 (onitis group)}

1. Metapleuron without posterior slit-like depression other Trieces species groups

- Metapleuron with distinct posterior slit-like depression (Figs 1E, 3E, 5E)

.2 (Trieces onitis group)

2. Occipital carina absent; ocellar area elevated; face black; metapleuron glabrous or sparsely setose

- Occipital carina present (Figs 1C, 3C, 5C); ocellar area flat; face yellow or with brownish patches (Figs 1B, 3B, 5B); metapleuron densely or moderately setose (Figs 1E, 3E, 5E)

3. Face as wide as long; antenna with 18-19 flagellomeres; first flagellomere $1.3 \times$ as long as wide [Japan and Russia] Trieces hokkaidensis Kusigemati, 1967

- Face wider than long; antenna with 22-23 flagellomeres; first flagellomere $1.6 \times$ as long as wide [Japan and Russia]

Trieces mandiblaris Kusigemati, 1971

4. Face completely yellow without brown patches (Fig. 1B); mandible with only upper tooth (Fig. 1D); antenna with 19 flagellomeres; first metasomal tergite with distinct wide, smooth longitudinal groove laterally (Fig. 2C); fore wing vein 1cu-a interstitial (Fig. 2B); temple posterior half yellow; mandible, scape and pedicel yellowish brown [India]

Trieces irwini sp. nov.

- Face yellow with midlongitudinal brown patches or entirely black with yellow spot antero-medially (Figs 3B, 5B); mandible with upper and lower teeth; antenna with 20-33 flagellomeres; first metasomal tergite without longitudinal groove laterally, if present then indistinct (Figs 4D, 6A); fore wing vein 1cu-a postfurcal (Figs 4B, 6C); temple posterior half black; mandible, scape and pedicel dark brown

5. Mesopleuron without longitudinal wrinkles posteriorly; metapleuron densely setose; propleuron densely setose; area superomedia smooth [Japan, Russia and South Korea]

Trieces homonae Kusigemati, 1967

- Mesopleuron with longitudinal wrinkles posteriorly (Figs 3E, 5E); metapleuron only posteriorly setose, rest glabrous (Figs 3E, 5E); propleuron glabrous (Figs 3E, 5E); area superomedia with wrinkles (Figs 4A, 5F)

6. Temple longer than transverse diameter of eye in lateral view; antenna with 33 flagellomeres; face black with yellow spot antero-medially; midlongitudinal carina of third metasomal tergite $0.7 \times$ as long as tergite [South Korea]

Trieces koreanus Choi \& Lee, 2016

- Temple shorter than transverse diameter of eye in lateral view (Figs 3E, 5E); antenna with 20-23 flagellomeres; face yellow with brown longitudinal patch medially; midlongitudinal carina of third metasomal tergite $0.5 \times$ as long as tergite (Figs $4 \mathrm{C}, 6 \mathrm{~B}$ ) 7

7. Metapleural slit short, isolated (Fig. 3E); metapleuron longitudinally striated (Fig. 3E); mesopleuron and propodeum distantly punctate (Figs 3E, 4A); submedial carinae of first metasomal tergite parallel posteriorly (Fig. 4C) [India]

Trieces isolatus sp. nov.

- Metapleural slit long, curved (Fig. 5E); metapleuron basal half smooth (Fig. 5E); mesopleuron and propodeum closely punctate (Figs 5E, F); submedial carinae of first metasomal tergite narrowing posteriorly (Fig. 6B) [India]

Trieces orientalis sp. nov. 


\section{Descriptions}

Trieces irwini sp. nov.

urn:1sid:zoobank.org:act:83D7FCCF-F4E7-41A0-B684-70D0F3AB89E9

Figs $1-2$

\section{Differential diagnosis}

The new species, Trieces irwini sp. nov. differs from the other species of the onitis group in having the following combination of characters: i) mandible has only upper tooth, ii) first metasomal tergite with ventro-lateral carina. This new species is more or less similar to $T$. homonae in having yellow face, but differs from the latter based on the following characters: mesopleuron with distinct longitudinal wrinkles posteriorly (vs without longitudinal wrinkles posteriorly in T. homonae), propodeum sparsely setose (vs densely setose in $T$. homonae), scutellum sparsely setose (vs densely setose in $T$. homonae), epicnemial carina joining with subtegular ridge (vs not joining with subtegular ridge in T. homonae).

\section{Etymology}

This species is named after veteran dipterologist Prof. Michael Edward Irwin (emeritus professor, University of Illinois, Urbana-Champaign, USA), who is a well-wisher and supporter of ATREE Insect taxonomy and Conservation Laboratory.

\section{Material examined}

\section{Holotype}

INDIA • ; Karnataka, Chamarajanagar, Biligiri Ranga Biligiri Rangaswamy Temple Tiger Reserve, Vellachy Metty; 14-30 Sep. 2005; Malaise trap; D.R. Priyadarsanan leg.; AIMB.

\section{Paratype}

INDIA -1 ₹; Karnataka, Chamarajanagar, Biligiri Ranga Hill Wild Life Sanctuary, Gombekallu; $11^{\circ} 54.363^{\prime}$ N, $77^{\circ} 11.235^{\prime}$ E; 17Aug.-21 Sep. 2006; Malaise trap; D.R. Priyadarsanan leg.; AIMB.

\section{Description}

\section{Female}

Measurements. Body length $5.5 \mathrm{~mm}$, length of fore wing $3.4 \mathrm{~mm}$.

HEAD. Head transverse in dorsal view, not narrowed posteriorly behind eyes, $1.8 \times$ as wide as long medially; frons smooth, setose; occiput smooth, glabrous medially rest setose; temple smooth dorsally, not convex, length $0.6 \times$ as long as transverse diameter of eye in lateral view. Occipital carina present. Eyes sparsely setose. Distance from lateral ocellus to eye equal to diameter of ocellus. Distance between lateral ocellus $2.0 \times$ distance from lateral ocellus to eye. Face not convex in lateral view, $1.4 \times$ as wide as long in anterior view, slightly narrowed posteriorly, smooth, setose. Clypeus separated from face by shallow depression, sculptured similar to face, with lower margin weakly convex in middle. Length of malar space equal to basal width of mandible. Mandible with only upper tooth. Antennae with 19 flagellomeres; all flagellomeres longer than wide; first flagellomere $1.6 \times$ as long as maximum width, $1.2 \times$ as long as second flagellomere.

Mesosoma. Mesosoma $1.6 \times$ as long as high; mesonotum densely, distantly punctate, interspace smooth, without notauli. Scutellum smooth, sparsely punctate with distinct lateral carina. Mesopleuron punctate with longitudinal wrinkles posteriorly, sparsely setose. Epicnemial carina distinct, reaching anterior margin of mesopleuron. Propodeum sparsely punctate anteriorly rest smooth with parallel longitudinal dorsal carinae; spiracles small, elliptical, separated from pleural carina. Metapleuron smooth, setose 
anteriorly rest glabrous, with distinct longitudinal slit and several short longitudinal rugae ventrally. Fore wing $3.7 \times$ as long as wide. Vein $1 \mathrm{cu}-\mathrm{a}$ weakly postfurcal. Hind femur $2.4 \times$ as long as its maximum width in lateral view. Hind tibia $3.0 \times$ as long as its maximum width. Ratio of length of hind tarsomeres 1-5, 3: 1.4: 1: 1: 1.6 .
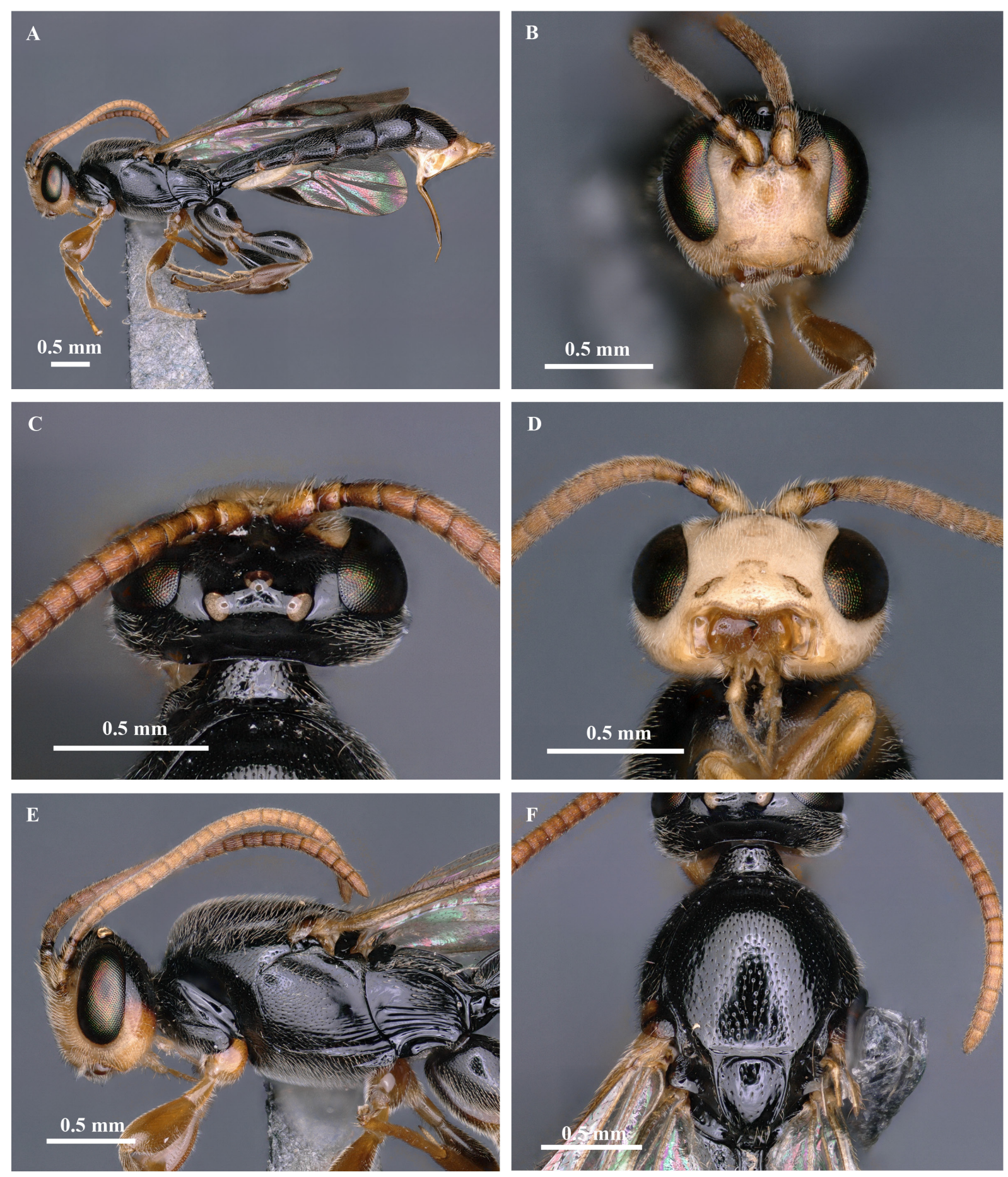

Fig. 1. Trieces irwini sp. nov., holotype, o (AIMB). A. Habitus, lateral view. B. Head, anterior view. C. Head, dorsal view. D. Head, ventral view. E. Head and mesosoma, lateral view. F. Mesosoma, dorsal view. 
Metasoma. Metasoma coarsely and densely punctate. First metasomal tergite $1.1 \times$ as long as apical width, with distinct dorso-lateral, ventro-lateral and pair of mid longitudinal carinae. Second metasomal tergite $0.7 \times$ as long as its apical width, with distinct dorso-lateral carina and midlongitudinal carinae. Third metasomal tergite $0.7 \times$ as long as its apical width, with dorso-lateral and midlongitudinal carinae distinct in basal half.
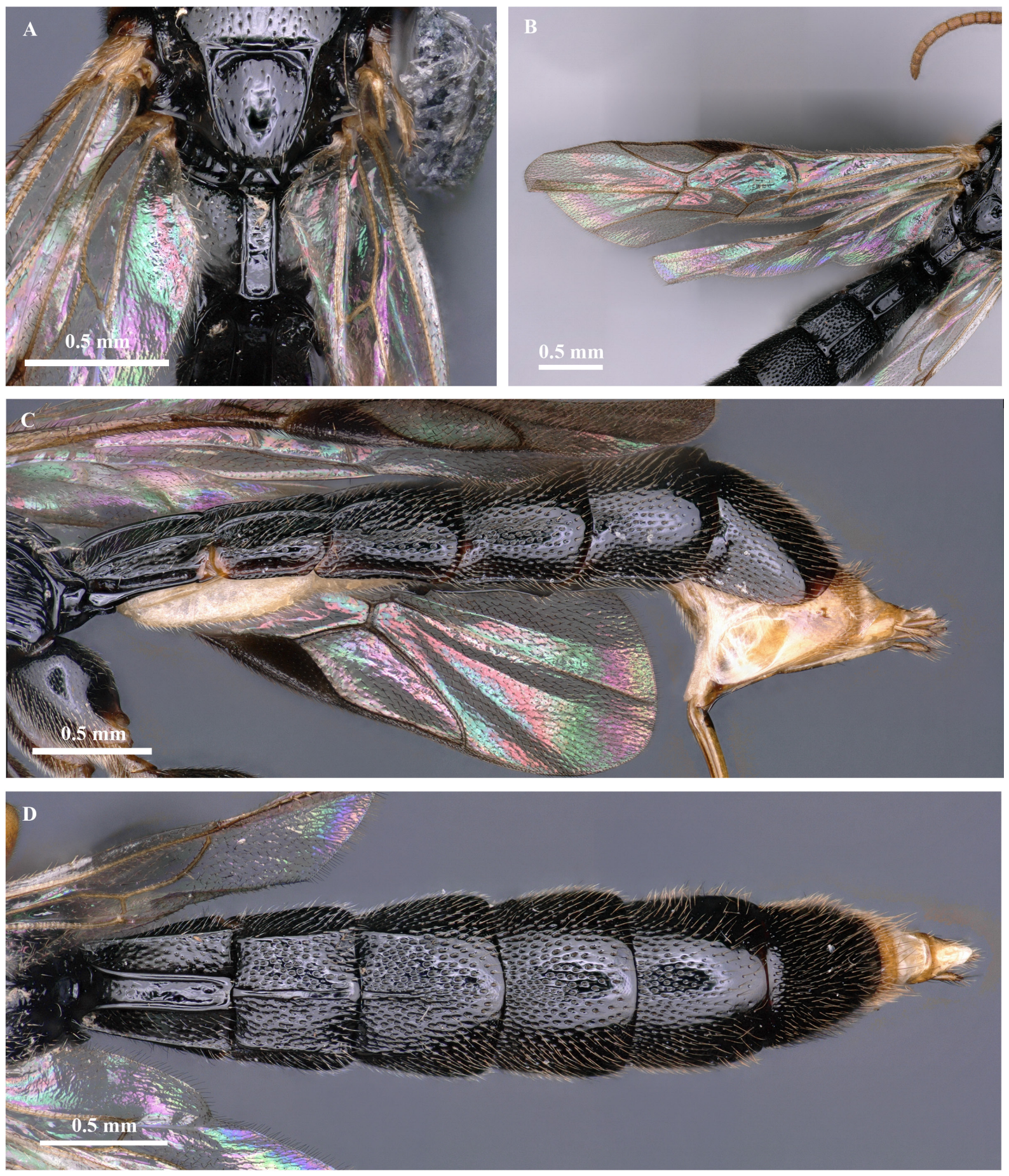

Fig. 2. Trieces irwini sp. nov., holotype, $\bigcirc$ (AIMB). A. Propodeum, dorsal view. B. Fore wing. C. Metasoma, lateral view. D. Metasoma, dorsal view. 
CoLor. Body mostly black; antennae, face, lateral temples posterior half, maxillary and labial palps, fore and mid legs, hind coxae apically, metasomal sternites and ovipositor sheath yellow to yellowish brown, hind tibiae, tarsi reddish brown.

\title{
Male
}

Same as female.

\section{Distribution}

India (Karnataka).

\section{Biology}

Unknown.

\author{
Trieces isolatus sp. nov. \\ urn:1sid:zoobank.org:act:4A160D4D-B82F-451B-91A7-7FA175BF0A8C
}

Figs $3-4$

\section{Differential diagnosis}

The new species comes closer to T. orientalis sp. nov. but differs based on the characters listed in the taxonomic key. Additionally, T. isolatus sp. nov. differs from the latter in having the following characters: hind coxa yellowish brown (vs black in T. orientalis sp. nov.), pterostigma yellow (vs black in T. orientalis sp. nov.), first metasomal tergite longer than wide (vs wider than long in T. orientalis sp. nov.), antenna with 20 flagellomeres (vs 23 in T. orientalis sp. nov.).

\section{Etymology}

The species name refers to the isolated pit below the metapleural slit.

\section{Material examined}

Holotype

INDIA - ; Karnataka, Chamarajanagar, Biligiri Ranga Hill Wild Life Sanctuary, Parasakatte; $12^{\circ} 01.414^{\prime} \mathrm{N}, 7^{\circ} 06.551^{\prime}$ E; 795 m a.s.1.; 30 Sep.-14 Oct. 2005; Malaise trap; D.R. Priyadarsanan leg.; AIMB.

\section{Description}

\section{Female}

Measurements. Body length $3.6 \mathrm{~mm}$, length of fore wing $2.4 \mathrm{~mm}$.

HEAD. Head transverse in dorsal view, not narrowed posteriorly behind eyes, $1.7 \times$ as wide as long medially; frons smooth, setose; occiput smooth, glabrous medially rest setose; temples smooth dorsally, setose, not convex, their length $0.7 \times$ as long as transverse eye diameter in lateral view. Occipital carina present. Eyes sparsely setose. Distance from lateral ocellus to eye equal to diameter of ocellus. Distance between lateral ocelli $2.0 \times$ distance from lateral ocellus to eye. Face not convex in lateral view, $0.9 \times$ as wide as long in anterior view, slightly narrowed posteriorly, punctate, setose. Clypeus separated from face by shallow indistinct depression, sculptured similarly to face, with lower margin weakly convex. Length of malar space equal to basal width of mandible. Mandible with upper and lower teeth. Antennae with 20 flagellomeres; all flagellomeres longer than wide; first flagellomere $1.3 \times$ as long as maximum width, as long as second flagellomere. 
Mesosoma. Mesosoma $1.6 \times$ as long as high; mesonotum densely, closely punctate, interspace smooth, without notauli. Scutellum smooth, with distinct lateral carina, distantly punctate. Mesopleuron punctate with longitudinal wrinkles, posteriorly setose. Epicnemial carina distinct, reaching anterior margin of mesopleuron. Propodeum distantly punctate with parallel longitudinal dorsal carinae; spiracles small,
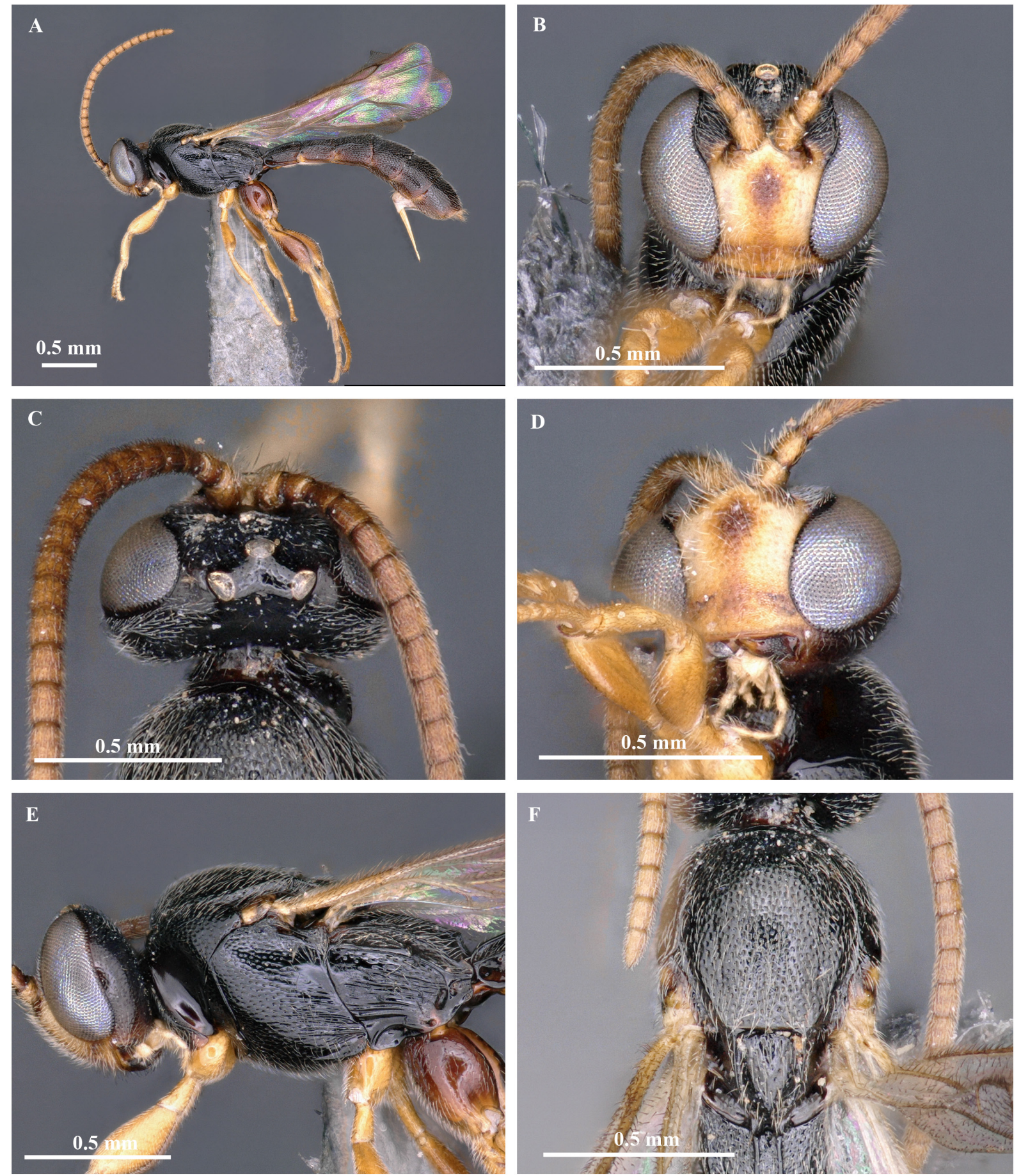

Fig. 3. Trieces isolatus sp. nov., holotype, $q$ (AIMB). A. Habitus, lateral view. B. Head, anterior view. C. Head, dorsal view. D. Head, latero-ventral view. E. Head and mesosoma, lateral view. F. Mesosoma, dorsal view. 
elliptical, separated from pleural carinae. Metapleuron smooth only at extreme base rest distinctly longitudinally striate, setose medially rest glabrous, with distinct isolated, longitudinal slit. Fore wing $3.4 \times$ as long as wide. Vein 1cu-a distinctly postfurcal. Hind femur $2.2 \times$ as long as its maximum width in lateral view. Hind tibia $3.0 \times$ as long as its maximum width. Ratio of length of hind tarsomeres $1-5$, 3: $1.5: 1.3: 1: 1.8$.
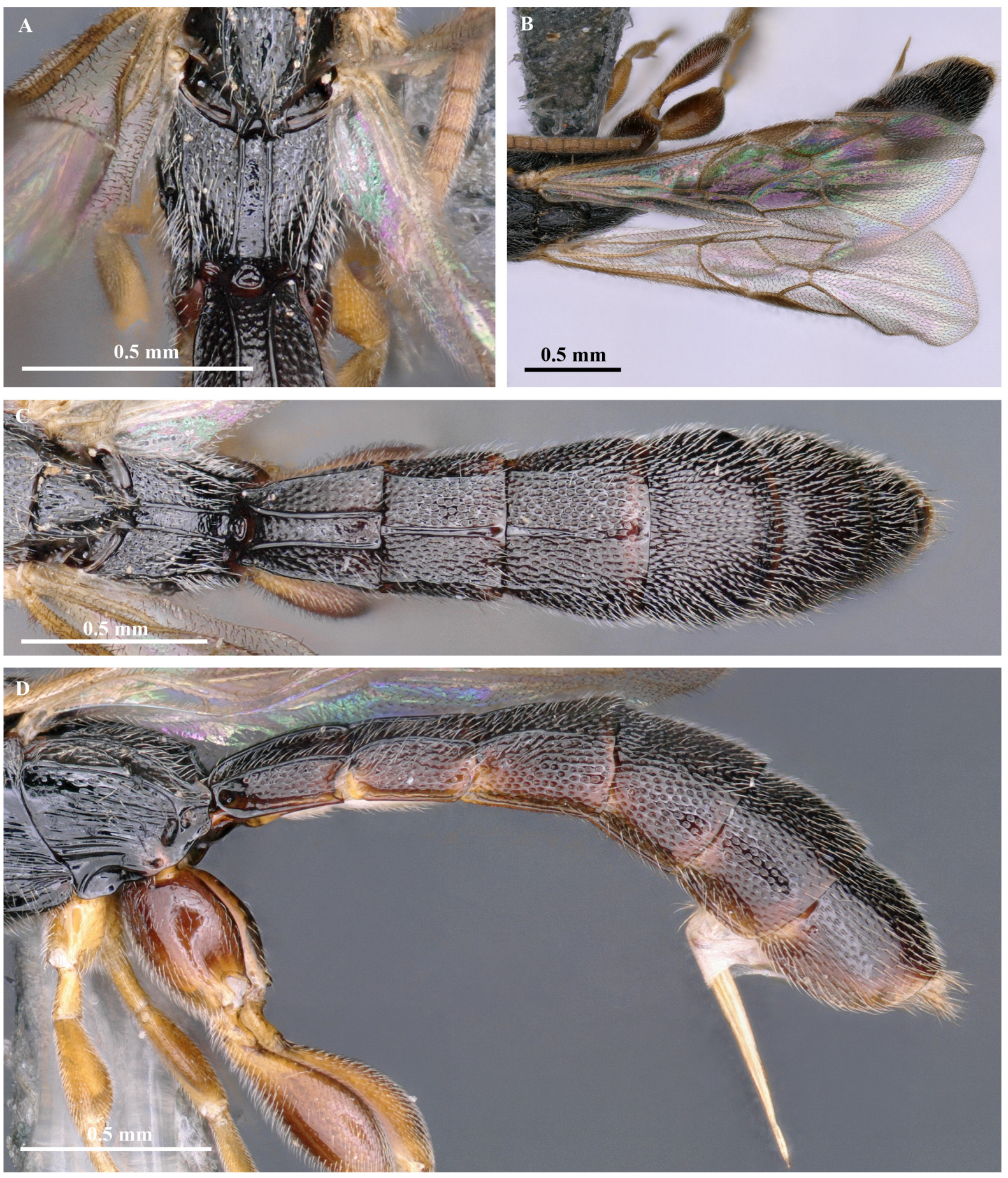

Fig. 4. Trieces isolatus sp. nov., holotype, $\odot$ (AIMB). A. Propodeum, dorsal view. B. Fore wing. C. Metasoma, dorsal view. D. Metasoma, lateral view. 
Metasoma. Metasoma coarsely and densely punctate. First metasomal tergite $1.1 \times$ as long as apical width, with distinct dorso-lateral and pair of mid longitudinal carinae, ventro-lateral carina absent. Second metasomal tergite $0.8 \times$ as long as its apical width, with distinct dorso-lateral carina and midlongitudinal carinae. Third metasomal tergite $0.8 \times$ as long as its apical width, with dorso-lateral and midlongitudinal carinae distinct in basal half.

COLOR. Body mostly blackish brown except antennae, face except medially, maxillary and labial palps, fore and mid legs, hind tibiae, tarsi, metasomal sternites, ovipositor sheath yellow.

\author{
Male \\ Unknown. \\ Distribution \\ India (Karnataka).
}

\title{
Biology
}

Unknown.

Trieces orientalis sp. nov.

urn:1sid:zoobank.org:act:0F5BBA69-7733-48FC-970B-FDF2A727CB9A

Figs 5-6

\section{Differential diagnosis}

The new species comes closer to T. koreanus but differs based on the characters listed in the taxonomic key. Additionally, T. orientalis sp. nov. differs from the latter in having the following characters: temple distinctly and closely punctate (vs sparse and indistinctly punctate in $T$. koreanus), first flagellomeres $1.6 \times$ as long as maximum width (vs first flagellomeres $1.9 \times$ as long as maximum width in $T$. koreanus), first metasomal tergite $0.8 \times$ as long as apical width (vs first metasomal tergite $1.7 \times$ as long as apical width in T. koreanus).

\section{Etymology}

The species is named after the distribution extension of the genus to the Indomalayan (= Oriental) region.

\section{Material examined}

\section{Holotype}

INDIA • ; N Nagaland, Zapami Village; $25^{\circ} 53.4^{\prime}$ N, 94²4.502' E; 18-21 Mar. 2021; Malaise trap; A.P. Ranjith leg.; AIMB.

\section{Description}

\section{Female}

Measurements. Body length $4.3 \mathrm{~mm}$, length of fore wing $2.6 \mathrm{~mm}$.

HEAD. Head transverse in dorsal view, not narrowed posteriorly behind eyes, $1.7 \times$ as wide as long medially; frons smooth, setose; occiput smooth, glabrous medially rest setose; temples smooth dorsally, not convex, their length $0.5 \times$ as long as transverse eye diameter in lateral view. Occipital carina present. Eyes sparsely setose. Distance from lateral ocellus to eye equal to diameter of ocellus. Distance between lateral ocellus $1.8 \times$ distance from lateral ocellus to eye. Face not convex in lateral view, $0.8 \times$ as wide as long in anterior view, slightly narrowed posteriorly, punctate, setose. Clypeus separated from face by 
shallow depression, sculptured similarly to face, with lower margin weakly convex in middle. Length of malar space equal to basal width of mandible. Mandible with upper and lower teeth. Antennae with 23 flagellomeres; all flagellomeres longer than wide; first flagellomere $1.6 \times$ as long as maximum width, as long as second flagellomere.
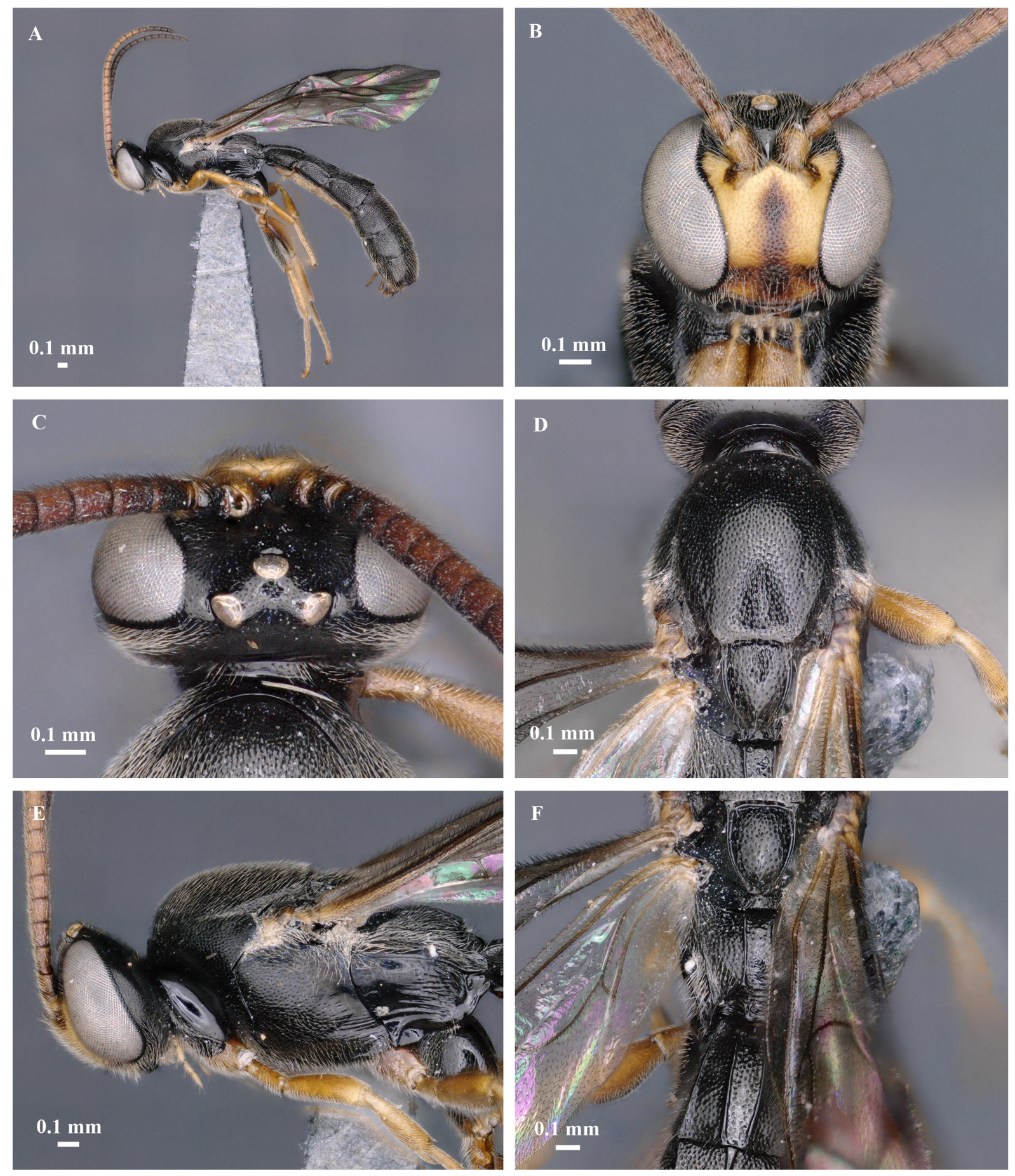

Fig. 5. Trieces orientalis sp. nov., holotype, $q$ (AIMB). A. Habitus, lateral view. B. Head, anterior view. C. Head, dorsal view. D. Mesosoma, dorsal view. E. Head and mesosoma, lateral view. F. Propodeum, dorsal view. 
Mesosoma. Mesosoma $1.6 \times$ as long as high; mesonotum densely, closely punctate, interspace smooth, without notauli. Scutellum smooth, closely punctate with distinct lateral carina. Mesopleuron punctate with longitudinal wrinkles posteriorly, setose. Epicnemial carina distinct, reaching anterior margin of mesopleuron. Propodeum punctate with parallel longitudinal dorsal carinae; spiracles small, elliptical, separated from pleural carinae. Metapleuron smooth, setose anteriorly and posteriorly rest glabrous, with distinct longitudinal slit and several short longitudinal rugae ventrally. Fore wing $3.2 \times$ as long as wide.
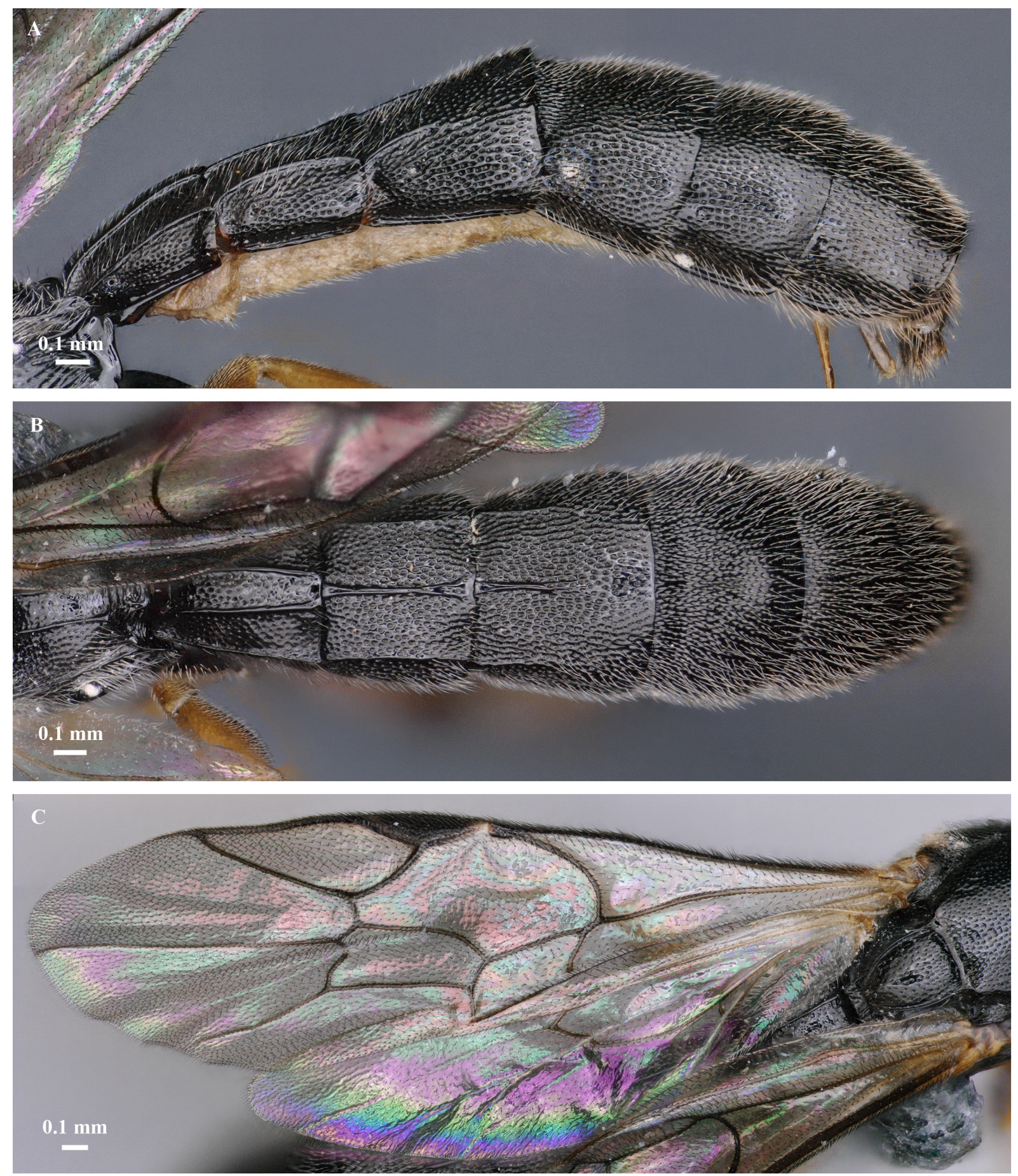

Fig. 6. Trieces orientalis sp. nov., holotype, $q$ (AIMB). A. Metasoma, lateral view. B. Metasoma, dorsal view. C. Fore wing. 
Vein 1 cu-a distinctly postfurcal. Hind femur $3.0 \times$ as long as its maximum width in lateral view. Hind tibia $3.9 \times$ as long as its maximum width. Ratio of length of hind tarsomeres $1-5,3.8: 1.8: 1.5: 1$ : 1.7 .

Metasoma. Metasoma coarsely and densely punctate. First metasomal tergite $0.8 \times$ as long as apical width, with distinct dorso-lateral and pair of mid longitudinal carinae, ventro-lateral carina absent. Second metasomal tergite $0.8 \times$ as long as its apical width, with distinct dorso-lateral carina and midlongitudinal
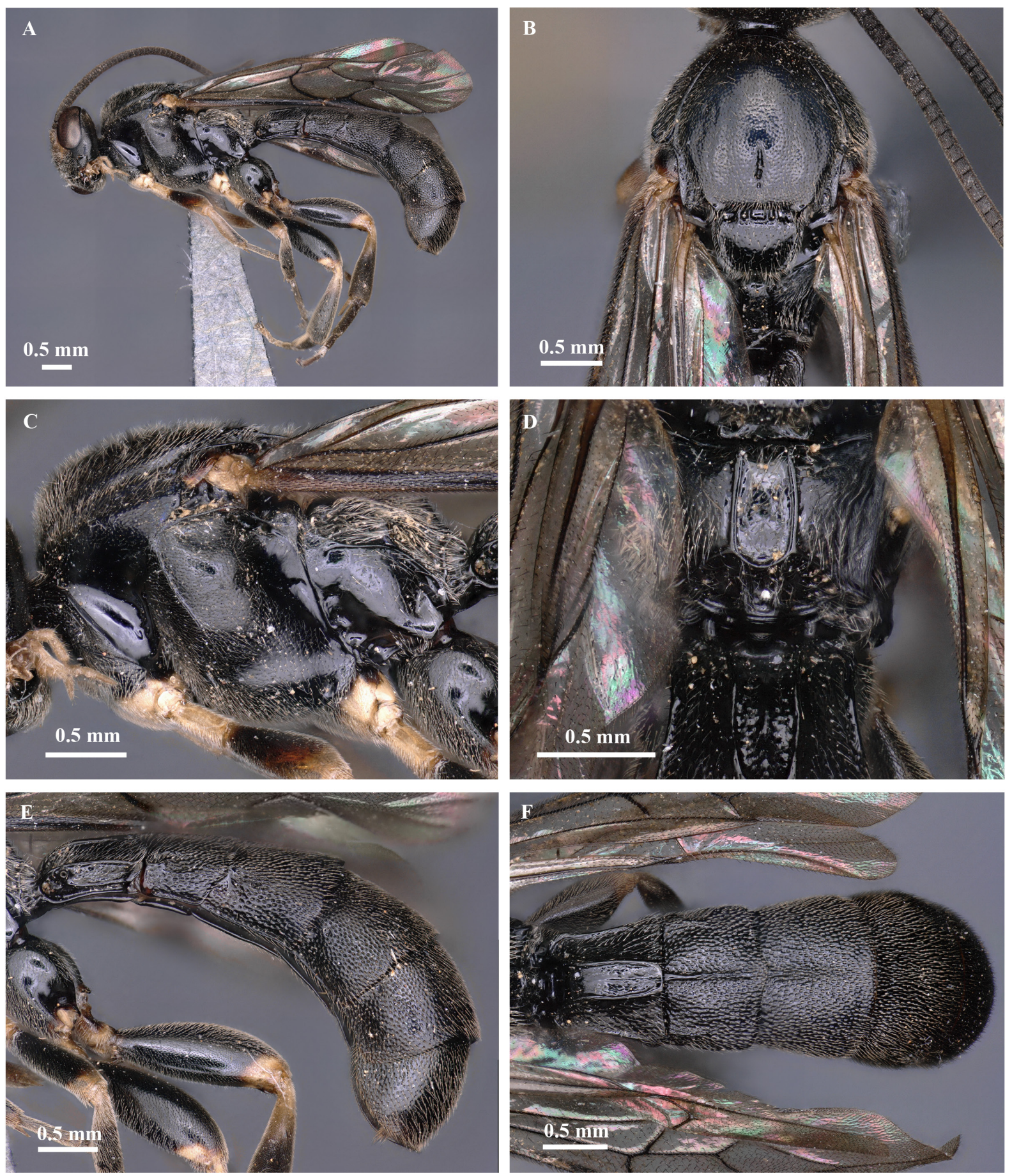

Fig. 7. Chorinaeus sp., §̊ (AIMB). A. Habitus, lateral view. B. Mesosoma, dorsal view. C. Mesosoma, lateral view. D. Propodeum, dorsal view. E. Metasoma, lateral view. F. Metasoma, dorsal view. 
carinae. Third metasomal tergite $0.7 \times$ as long as its apical width, with dorso-lateral and midlongitudinal carinae distinct in basal half.

Color. Body black except antennae, face, maxillary and labial palps, fore and mid legs, hind coxae apically, hind tibiae, tarsi, metasomal sternites, ovipositor sheath yellow to yellowish brown.

\author{
Male \\ Unknown \\ Distribution \\ India (Nagaland).
}

\title{
Biology
}

Unknown.

\section{Discussion}

\section{Redefinition and character plasticity of onitis species group}

Townes \& Townes (1959) defined the onitis species group of the genus Trieces based on the following morphological characters: head wide to very wide; eyes sparsely setose; metapleuron setose anteriorly, with longitudinal wrinkles on posterior half and a distinct posterior slit-like depression. Presence of the metapleural slit is considered an apomorphic character of the species group (Kusigemati 1967; Tolkanitz 2010). Earlier studies have suggested that the presence of an occipital carina is a character of generic importance (Townes \& Townes 1959), but in some species this character is found to be very plastic as occipital carina is absent in some species such as T. hokkaidensis and T. mandiblaris. So, even though the occipital carina is absent in two Eastern Palearctic species, T. hokkaidensis and T. mandiblaris are included in the onitis species group based on the presence of the metapleural slit (Kusigemati 1967, 1971; Tolkanitz 2010). Moreover, the addition of $T$. homonae to this group is supported by the presence of a metapleural slit, irrespective of the absence of longitudinal wrinkles on mesopleuron. The new species described in the present study point to the metapleural slit being the only constant character for this group.

Species of this group exhibit a very wide face (1.5-2.25 $\times$ as wide as long) in general (Walley 1969). But in the new species T. orientalis sp. nov. and T. irwini sp. nov., the face is not as wide as in other species of the group $(<1.5 \times$ as wide as long). This leads to the notion that Indomalayan species of the onitis group differ markedly and can form a different clade within the group. Generally, in species of this group, the median and lateral longitudinal carinae extend to the anterior half of the third metasomal tergite (Walley 1969). It is noted that the midlongitudinal carina extends $3 / 4$ the length of the tergite in T. koreanus (Choi et al. 2016). By considering all these morphologically variable characters it is important to mention that the character boundaries of onitis group of Trieces are more extending than previously assumed. Considering the newly defined characters like longer face and reduced number of flagellomeres suggest that Indomalayan fauna of Trieces of onitis group might form a different clade among the other species. Species delimitation and sexual dimorphism in the onitis group can be identified by the difference in number of flagellomeres (Walley 1969). Species of this group have at least 24 flagellomeres. In the Nearctic region the intraspecific variation based on the number of flagellomeres ranges from 1 to 6 segments (Walley 1969). This trend in the difference of number of the flagellomeres between males and females can also be expected in the Palearctic and Oriental faunas by studying the male of the new species described here.

\section{Distribution of Trieces}

Species of Trieces have been described from the Afrotropical, Nearctic, Neotropical and Palearctic regions so far, but the existence of undescribed species from other regions has been published (Townes \& Townes 1959; Gauld 1984; Yu et al. 2016). Until now no species has been taxonomically described from the 
Indomalayan region. The present study confirms the distribution of Trieces to this region. The discovery of species of Trieces from the Indomalayan region fairly supports the observation of Townes \& Townes (1959), where they mentioned the occurrence of undescribed species from the Philippines. It is important to note that the distribution range of none of the known species overlaps two different zoogeographical regions. Until now, most of the species have been collected from dry habitats (Gauld et al. 2002). The species described in this paper are collected from dry deciduous, evergreen and wet forests of the Biligiri Rangaswamy Hills, Karnataka and Zapami Village, Nagaland. This fairly supports the fact that species of Trieces can also withstand wet climates. Species of Trieces are more abundant in the Northern Hemisphere and only 15 species are known from the Southern Hemisphere (Benoit 1955; Gauld et al. 2002; Mazón \& Bordera, 2016; Yu et al. 2016). Gauld (1984) pointed to the occurrence of undescribed species from Australian region. The present study fairly supports the increased abundance pattern in the Northern Hemisphere.

\section{Acknowledgments}

We acknowledge the financial assistance of the Department of Biotechnology, Government of India, through a major research project on Bio-resource and Sustainable livelihoods in North East India (BT/01/17/NE/TAX) which was instrumental for the collection of specimen from Nagaland. DRP is thankful to the Schlinger Foundation, USA, for the support through the Western Ghats Insect Inventory Program. We are thankful to the section editor and reviewers for the comments and suggestions to the manuscript.

\section{References}

Aeschlimann J.P. 1973. Révision des espèces ouest-paléarctiques du genre Trieces (Hym., Ichneumonidae). Annales de la Société entomologique de France 9 (4): 975-988.

Aeschlimann J.P. 1975. Révision des espèces ouest-paléarctiques du genre Chorinaeus Holmgreen (Hymenoptera, Ichneumonidae). Annales de la Société entomologique de France 2 (4): 723-744.

Benoit P.L.G. 1955. Contributions à l'etude de la faune entomologique de Ruanda-Urundi (Missions P. Basilewsky 1953). XXXVIII. Hymenoptera Ichneumonidae (Pars 1). Annales du Musée royal du Congo belge, Sciences zoologiques 36: 329-346.

Broad G.R., Shaw M.R. \& Fitton M.G. 2018. Ichneumonid wasps (Hymenoptera: Ichneumonidae): their classification and biology. Handbooks for the Identification of British Insects 7 (12): 1-418.

Choi J.-K., Suh K.-I. \& Lee J.-W. 2016. First records of three genera of Metopiinae (Hymenoptera, Ichneumonidae) from South Korea with description of one new species. Journal of Asia-Pacific Biodiversity 9 (4): 461-467. https://doi.org/10.1016/j.japb.2016.05.001

Eady R.D. 1968. Some illustrations of microsculpture in the Hymenoptera. Proceedings of the Royal Entomological Society of London (A) 43: 66-72. https://doi.org/10.1111/j.1365-3032.1968.tb01029.x

Gauld I.D. 1984. An Introduction to the Ichneumonidae of Australia. With a Contribution on Metopiinae by M. G. Fitton. British Museum (Natural History), London.

Gauld I., Sithole R., Ugalde J. \& Godoy C. 2002. The Ichneumonidae of Costa Rica, 4. Memoirs of the American Entomological Institute. Vol. 66. American Entomological Institute, Gainesville, Florida.

Kusigemati K. 1967. Descriptions of four new species of the genus Trieces Townes from Japan (Hymenoptera: Ichneumonidae). Insecta Matsumurana 29: 45-49.

Kusigemati K. 1971. Taxonomic studies on the subfamily Metopiinae of Japan (Hymenoptera: Ichneumonidae). Memoirs of the Faculty of Agriculture, Kagoshima University 8 (1): 205-298. 
Mazón M. \& Bordera S. 2016. Description of the first species of Trieces (Hymenoptera: Ichneumonidae) with tyloids in the male antennae and new records of Neotropical species. Neotropical Entomology 45 (3): 280-287. https://doi.org/10.1007/s13744-016-0381-2

Mazón M. \& Bordera S. 2020. Discovery of a new species of Trieces (Hymenoptera: Ichneumonidae: Metopiinae) questioning the traditional delimitation between Trieces and Chorinaeus. Zootaxa 4821 (3): 594-600. https://doi.org/10.11646/zootaxa.4821.3.10

Mazón M. \& Bordera S. 2021. Trieces ranjithi nom. nov., a replacement name for Trieces confusus Mazón \& Bordera, 2020 (Hymenoptera: Ichneumonidae: Metopiinae). Zootaxa 5005 (1): 85. https://doi.org/10.11646/zootaxa.5005.1.6

Melo I.F.D., Araújo C.R. \& Penteado-Dias A.M. 2015. New species of Exochus Gravenhorst and Trieces Townes (Hymenoptera, Ichneumonidae, Metopiinae) and first record of seven species from Brazil. Zootaxa 4059 (1): 40-50. https://doi.org/10.11646/zootaxa.4059.1.2

Tolkanitz V.I. 2010. Ichneumon flies of the genus Trieces (Hymenoptera, Ichneumonidae, Metopiinae) in the Palearctic fauna. Entomological Review 90 (4): 465-472. https://doi.org/10.1134/S001387381004007X

Townes H. 1946. The generic position of the Neotropic Ichneumonidae (Hymenoptera) with types in the Philadelphia and Quebec museums, described by Cresson, Hoolter, Norton, Provancher, and Viereck. Boletín de Entomologia Venezolana 5 (2): 29-63.

Townes H.K. 1971. Genera of Ichneumonidae. 4. Memoirs of the American Entomological Institute. Vol. 17. American Entomological Institute, Gainesville, Florida.

Townes H.K. \& Townes M. 1959. Ichneumon-flies of American north of Mexico: 1. Subfamily Metopiinae. United States National Museum Bulletin 216 (1): 1-318. https://doi.org/10.5479/si.03629236.216.1

Walley G.S. 1969. A synopsis of the Nearctic species of the onitis group of the genus Trieces (Hymenoptera: Ichneumonidae). Canadian Entomologist 101: 1092-1106. https://doi.org/10.4039/Ent1011092-10

Yu D.S., van Achterberg K. \& Horstmann K. 2016 World Ichneumonoidea 2015. Taxonomy, Biology, Morphology and Distribution. In: Taxapad interactive Catalogue Database. Nepean, Ottawa. [on flashdrive]

Zhang Y., Sheng M-L. \& Xiong Z-C. 2016. A new species of Metopiinae (Hymenoptera, Ichneumonidae) parasitizing lepidopteran larvae in China. ZooKeys 572: 71-79. https://doi.org/10.3897/zookeys.572.8031

Manuscript received: 23 September 2021

Manuscript accepted: 1 December 2021

Published on: 10 February 2022

Topic editor: Tony Robillard

Section editor: Gavin Broad

Desk editor: Radka Rosenbaumová

Printed versions of all papers are also deposited in the libraries of the institutes that are members of the EJT consortium: Muséum national d'histoire naturelle, Paris, France; Meise Botanic Garden, Belgium; Royal Museum for Central Africa, Tervuren, Belgium; Royal Belgian Institute of Natural Sciences, Brussels, Belgium; Natural History Museum of Denmark, Copenhagen, Denmark; Naturalis Biodiversity Center, Leiden, the Netherlands; Museo Nacional de Ciencias Naturales-CSIC, Madrid, Spain; Real Jardín Botánico de Madrid CSIC, Spain; Zoological Research Museum Alexander Koenig, Bonn, Germany; National Museum, Prague, Czech Republic. 